\title{
A review of contingency management for the treatment of substance-use disorders: adaptation for underserved populations, use of experimental technologies, and personalized optimization strategies
}

This article was published in the following Dove Press journal: Substance Abuse and Rehabilitation

\author{
Sterling M McPherson ${ }^{1-4}$ \\ Ekaterina Burduli ${ }^{1-5}$ \\ Crystal Lederhos Smith ${ }^{1-4}$ \\ Jalene Herron ${ }^{2,6}$ \\ Oladunni Oluwoye $e^{2,6}$ \\ Katherine Hirchak ${ }^{2-4}$ \\ Michael F Orr ${ }^{1-5}$ \\ Michael G McDonell ${ }^{1-5}$ \\ John M Roll ${ }^{1-5}$ \\ 'Department of Medical Education \\ and Clinical Sciences, Elson S Floyd \\ College of Medicine, Washington State \\ University, ${ }^{2}$ Programs of Excellence \\ in Addictions Research, Washington \\ State University, ${ }^{3}$ Analytics and \\ Psychopharmacology Laboratory \\ (APPL), Washington State University, \\ ${ }^{4}$ Translational Addictions Research \\ Center, Washington State University, \\ ${ }^{5}$ College of Nursing, Washington \\ State University, ${ }^{6}$ Behavioral Health \\ Interventions (BHI), Washington State \\ University, Spokane, WA, USA
}

Correspondence: Sterling M McPherson Department of Medical Education and Clinical Sciences, Elson S Floyd College of Medicine, Washington State University, PO Box 1495, Spokane, WA 99210, USA Email sterling.mcpherson@wsu.edu

\begin{abstract}
This review of contingency management (CM; the behavior-modification method of providing reinforcement in exchange for objective evidence of a desired behavior) for the treatment of substance-use disorders (SUDs) begins by describing the origins of CM and how it has come to be most commonly used during the treatment of SUDs. Our core objective is to review, describe, and discuss three ongoing critical advancements in CM. We review key emerging areas wherein CM will likely have an impact. In total, we qualitatively reviewed 31 studies in a systematic fashion after searching PubMed and Google Scholar. We then describe and highlight CM investigations across three broad themes: adapting CM for underserved populations, CM with experimental technologies, and optimizing CM for personalized interventions. Technological innovations that allow for mobile delivery of reinforcers in exchange for objective evidence of a desired behavior will likely expand the possible applications of CM throughout the SUD-treatment domain and into therapeutically related areas (eg, serious mental illness). When this mobile technology is coupled with new, easy-to-utilize biomarkers, the adaptation for individual goal setting and delivery of CM-based SUD treatment in hard-toreach places (eg, rural locations) can have a sustained impact on communities most affected by these disorders. In conclusion, there is still much to be done, not only technologically but also in convincing policy makers to adopt this well-established, cost-effective, and evidence-based method of behavior modification.
\end{abstract}

Keywords: contingency management, novel substance-use treatment technologies, drug- and alcohol-use biomarkers, substance-use disorder treatment

\section{Introduction}

Contingency management $(\mathrm{CM})$ is an effective behavioral treatment approach commonly applied to substance-use disorders (SUDs). CM has a long history in basic and clinical research and a deep theoretical background for virtually all types of use disorders. ${ }^{1}$ Interestingly, while CM was applied first to the field of alcohol-use disorders, ${ }^{2-5}$ only now, after a protracted dormancy in that field, is CM being applied in a manner consistent with what has become a largely standardized approach in the field of drug abuse (ie, delivery of reinforcers in exchange for biochemically verified abstinence) to increase abstinence significantly and consistently. ${ }^{6,7}$ 
Early on, after being utilized for alcohol-use disorders, $\mathrm{CM}$ was applied among students with intellectual disabilities. ${ }^{8}$ Following that, it was used for smoking ${ }^{9}$ and has since then been used primarily for SUD-treatment development. ${ }^{10}$ It has also been used to alter a variety of other behaviors, some closely related to substance use, but increasingly among broader, related health behavior, such as HIV-risk behavior. ${ }^{8}$ Given the considerable evidence that has accumulated over many decades, CM has been demonstrated clearly to be one of the most effective behavioral interventions for initiating and maintaining abstinence from alcohol and drugs. ${ }^{11} \mathrm{CM}$ 's history in the field of alcohol-use disorder-treatment research is noted herein while discussing innovations in remote technology and biomarker development that may be major antecedents for key developments in the implementation of CM across SUD treatment generally.

We briefly discuss the background of $\mathrm{CM}$ and how it has been used. We then spend most of this review discussing innovative developments within the SUD-treatment literature and how $\mathrm{CM}$ can play a unique and increasingly significant role in SUD treatment if political and implementation barriers can be overcome. Our core objective is to review, describe, and discuss three critical advancements of CM currently happening (ie, adapting CM for underserved populations, $\mathrm{CM}$ with experimental technologies, and optimizing CM for personalized interventions). We close by speculating on possible future directions and methods of maximizing the impact of CM, an area we view as largely underdeveloped.

\section{Conceptual background of CM}

CM-based treatments for SUDs originate in basic behavioral science, namely the operant-conditioning literature. Operant conditioning is a type of learning where the operant (ie, behavior) is maintained or modified via behavioral consequences. CM was born out of the early observation that SUDs largely exemplify reinforced operant behavior. As such, these behaviors can be modified effectively through altering the behavioral consequences. In such a framework, consequences are classified as positive reinforcements (ie, delivering tangible consequences to increase desired behavior), negative reinforcements (ie, removing an aversive stimulus to increase desired behavior), positive punishments (ie, delivering a punishing consequence to reduce an undesired behavior), or negative punishments (ie, removing a positive reinforcer to reduce an undesired behavior). Three key principles of CM are the rate of reinforcement (ie, the amount of reinforcement per behavior), immediacy of the reinforcer being delivered (ie, exchange delays), and the magnitude or size of the reinforcer. These three elements were identified in the behavior-modification literature long before $\mathrm{CM}$ was introduced, and they have shaped several lines of work within the $\mathrm{CM}$ literature. ${ }^{12,13}$ While there has been much work on these three principles in both animal and human laboratories that we will not cover here, this work has often given way to more or less "standard" uses of CM as part of "treatment as usual" packages for various experimental treatments. ${ }^{14}$

CM typically modifies behavior by delivering tangible reinforcements (eg, prizes, vouchers, or monetary reinforcement) in exchange for evidence of the desired behavior (eg, abstinence, decreased drug use, consumption of prescribed methadone) or by withholding those reinforcers in instances of undesired behavior (eg, drinking).${ }^{15}$ The reinforcers are dependent on objective evidence of the desired behavior, such as biochemically verified alcohol or drug abstinence, treatment attendance, or medication adherence. Importantly, this underlying rationale does not eliminate other sources of influence on drug-abuse behavior, but it does provide key opportunities for modification in an effort to decrease drug and alcohol abuse or drug self-administration. Although both reinforcing and punishing contingencies can be effective for treatment of SUDs, punishing contingencies can worsen undesirable behaviors without thoughtful development of this contingency. ${ }^{16}$ The vast majority of CM treatments for SUDs apply positive reinforcement. The efficacy of CM has been shown repeatedly in the treatment of SUDs; however, two key multisite clinical trials definitively demonstrated the efficacy of CM for stimulant-use disorder, both in a psychosocial treatment setting and in methadone-maintenance settings across several nationally distributed sites..$^{17,18}$

The immediacy of the reinforcer in CM may work as a result of the removal of delay discounting in substance users. Delay discounting, the tendency to devalue positive reinforcement that a subject must wait for, is common in drug-abusing persons. ${ }^{19}$ This may be a result of an imbalance in neural systems within the drug abuser. ${ }^{20,21}$ Specifically, it is theorized that the planning and forward looking to reinforcement or consequence of the prefrontal cortex is overridden by an overactive amygdala system, which promotes the subject's interest in immediate reinforcement. ${ }^{22}$

\section{Current evidence base and rationale for review}

$\mathrm{CM}$ has an extraordinarily strong evidence base and is a demonstrably cost-effective technique ${ }^{23-28}$ that has been used successfully for decades to promote abstinence from benzo- 
diazepines, ${ }^{29}$ cocaine,${ }^{30}$ tobacco,${ }^{31}$ opiates,${ }^{32,33}$ alcohol,,${ }^{6,7}$ marijuana, ${ }^{34,35}$ and methamphetamine. ${ }^{13,36,37}$ Several large clinical trials and three meta-analyses support its efficacy. ${ }^{18,38-40}$ In fact, one meta-analysis found that CM resulted in successful treatment episodes $61 \%$ of the time compared to $39 \%$ for other modalities. ${ }^{38}$ There have been some clinical trials that have found that $\mathrm{CM}$ leads to reductions in drug use that persist for 12-18 months after treatment completion, ${ }^{41-44}$ although results have not been consistent across all studies. Longer-term effects of CM are one important area in need of additional research. Notably, relapse is common among people who suffer from SUDs, regardless of the treatment they receive. ${ }^{45-48}$ Further, it is important to note that CM's consistent, statistically significant treatment effects across diverse clinical trials may be indicative of $\mathrm{CM}$ also being associated with better long-term treatment outcomes compared to other psychosocial interventions. This is in part due to an evidence base indicating that longer abstinence during SUD treatment is associated with better long-term treatment outcomes. ${ }^{49-51}$

We focus on current, novel innovations within the field of SUD treatment with CM that have unique capacities to be leveraged by existing CM behavior-science techniques. We also discuss several populations for which CM may be adapted and/or modified for specific comorbidities or other complications. Moreover, it is also possible that because of these innovations, $\mathrm{CM}$ could be exceptionally well positioned to be modified and adapted to create a new generation of CM techniques that could be used to produce behavior change in a scalable fashion for hard-to-reach populations, such as those living in areas where both financial resources and clinical expertise are scarce. This is the rationale that shaped our primary objective of this systematic review: to review, describe, and discuss three critical advancements of CM currently happening: adapting $\mathrm{CM}$ for underserved populations, $\mathrm{CM}$ with experimental technologies, and optimizing $\mathrm{CM}$ for personalized interventions.

\section{Methods}

\section{Search strategy}

In September 2017, we sought publications in the PubMed database, the search engine of the US National Library of Medicine, and Google Scholar, a free and openly available database for biomedical researchers. The search period was specified for the years 2000-2017. Articles had to be written in English and involve human subjects. The search strategy encompassed three broad a priori themes across CM: CM treatment in underserved populations, novel CM-technology applications, and personalized CM interventions. Research articles were retrieved using the following search terms for the aforementioned years and databases: CM, CM addiction treatment, $\mathrm{CM}$ treatment for underserved populations, $\mathrm{CM}$ and SUD treatment, CM and alcohol-use biomarkers, personalized CM interventions, CM medication adherence, mobile CM delivery, novel substance-use treatment technologies, and novel CM technologies. Once unique publications had been identified, we reviewed their reference lists for additional relevant literature.

We culled the initial list extensively for relevance before deciding which articles to include in our review. In addition to the specified search criteria, we included meta-analyses and a couple of noted classic CM works prior to the year 2000. This was done because there were some CM-optimization strategies tested before 2000, but that work has not been picked up to any degree of finality since then. We include those works here in an effort to help shape the review and discussion of how best to optimize CM, especially in light of emerging technology and reaching underserved populations (our other two themes of this review). In addition, we searched reference sections of review papers and CM metaanalyses that have been published. Authors worked in pairs to review articles for inclusion, and discrepancies were resolved through discussion. In the end, all articles were reviewed and approved for inclusion by the authors involved in writing this review prior to paper finalization.

\section{Search results}

The final 31 studies included in this review are categorized by our three overarching themes of CM treatment in underserved populations (Table 1), novel CM-technology applications (Table 2), and personalized CM interventions (Table 3). We discuss these three themes extensively, and each table includes critical study characteristics for our three themes.

\section{Results \\ Adapting CM for underserved populations} Co-occurring SUDs and serious mental illness (SMI) $\mathrm{CM}$ has been an effective strategy for reducing alcohol and drug use in several clinical trials conducted among individuals with co-occurring SUDs and SMI. ${ }^{6,18,52-54}$ In their definitive multisite national clinical trial, Peirce et al demonstrated that CM can significantly increase cocaine (and alcohol) abstinence among patients receiving methadone maintenance compared to those receiving methadone maintenance alone. In this study, the cost of the incentives used to increase 


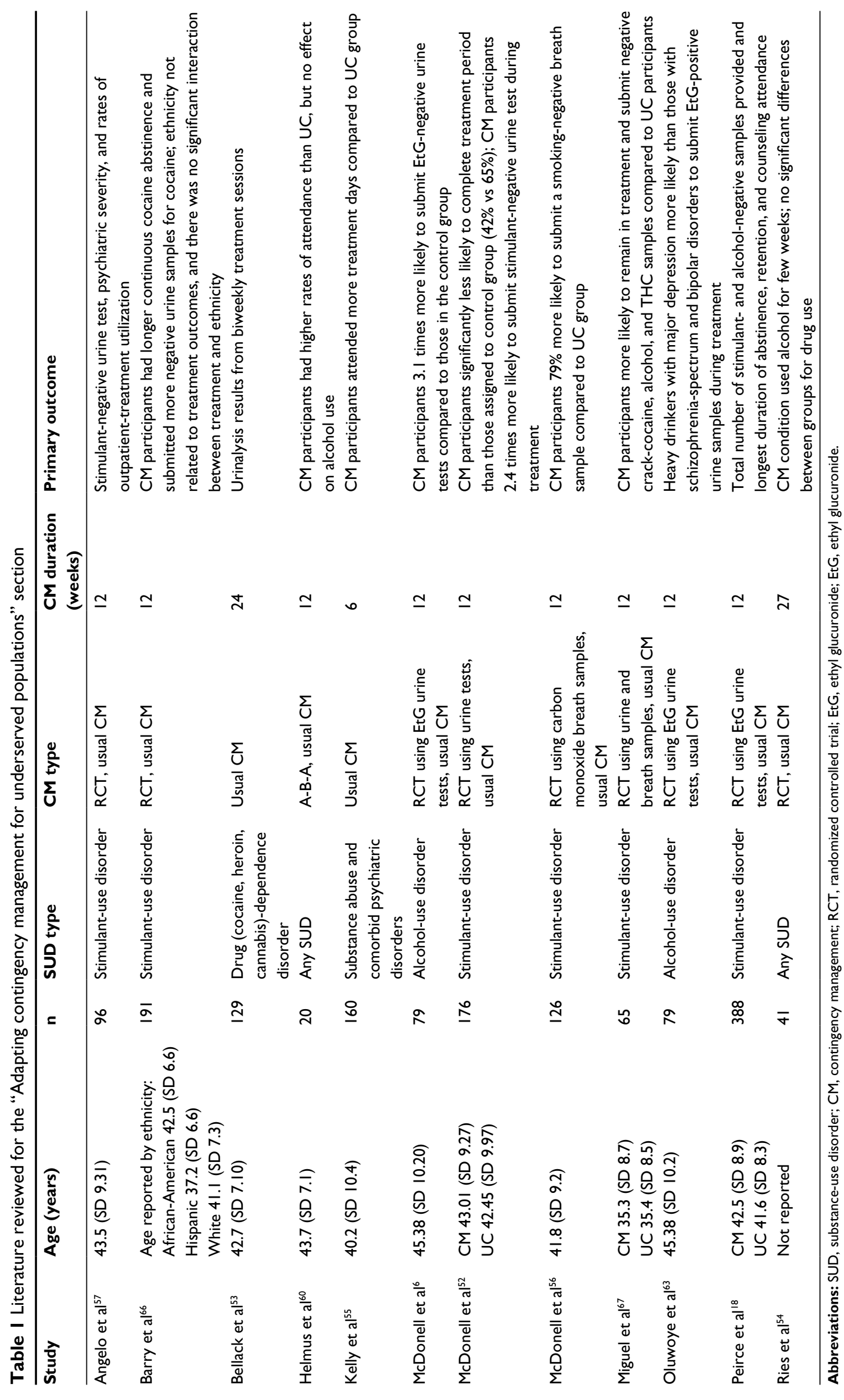




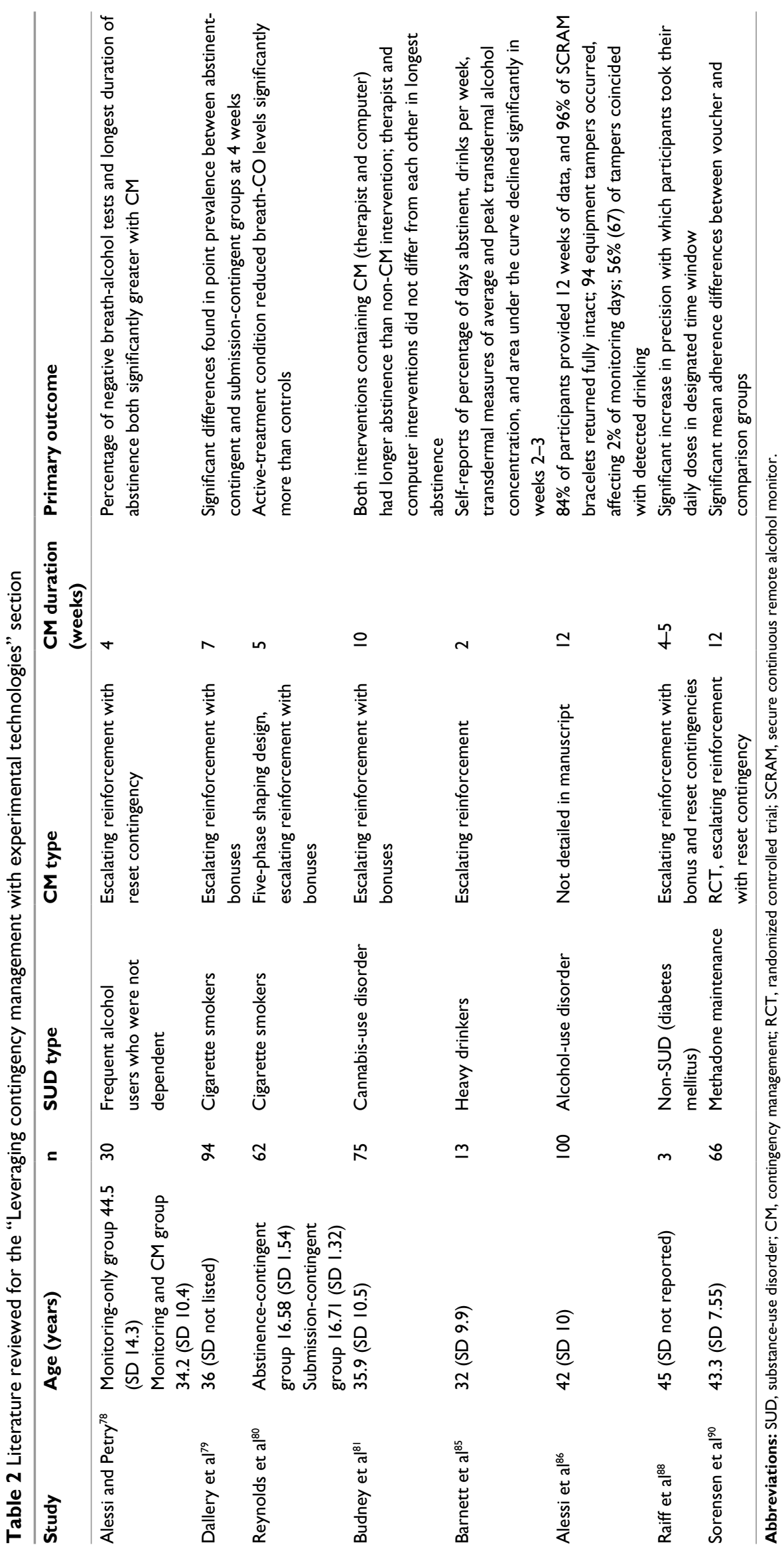




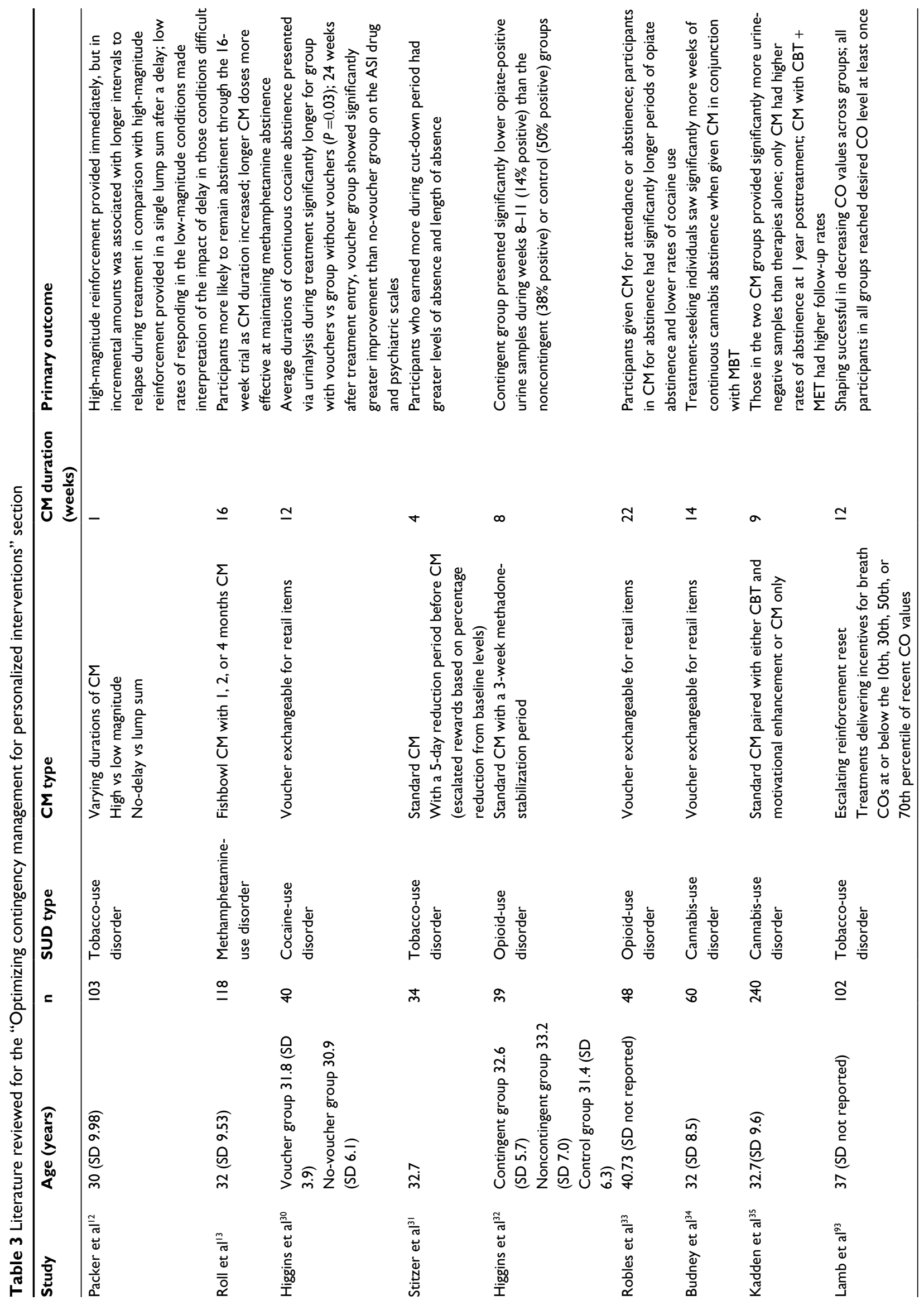




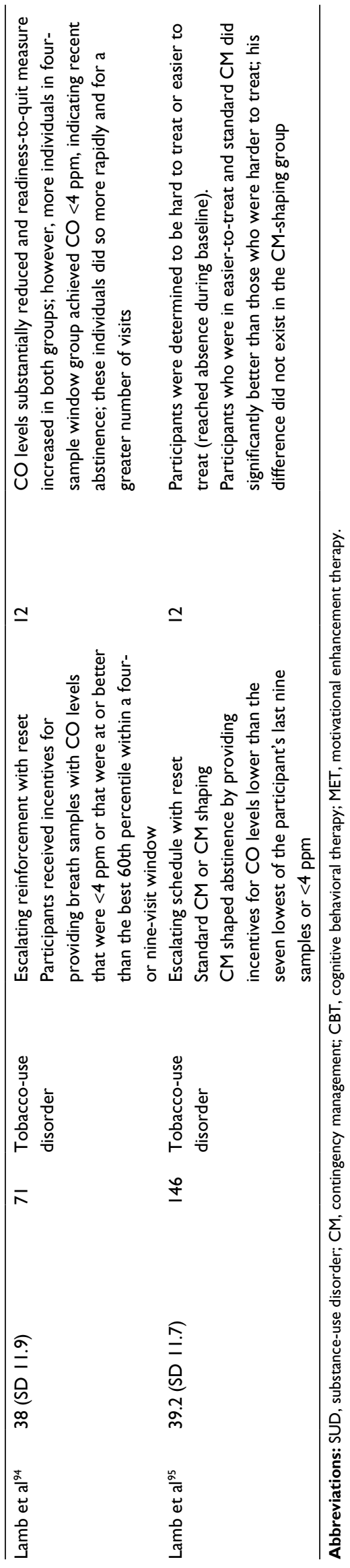

abstinence was also noteworthy, costing on average US\$120 per patient. ${ }^{18}$ In another clinical trial, Bellack et al used a cognitive behavioral therapy (CBT) intervention that included $\mathrm{CM}$ to treat outpatients with SUDs and SMI. Participants randomized to the treatment condition had higher rates of drug abstinence, improved quality of life, and lower rates of inpatient-treatment episodes compared to those randomized to the control condition. ${ }^{53}$

In a smaller study of just 41 adults with SMI and SUDs, individuals who received access to Social Security benefits contingent on alcohol and drug abstinence achieved higher rates of abstinence than those randomized to the control condition. ${ }^{54}$ Among a sample of 160 adults with dual diagnoses that included co-occurring SUDs, participants enrolled in the $\mathrm{CM}$ condition received prizes or reinforcement in exchange for treatment attendance. Participants enrolled in the CM condition were approximately twice as likely to remain in treatment longer than those in the control condition. ${ }^{55}$ However, this study found no significant differences between participants in the CM and control conditions in levels of depression, anxiety, stress, drug cravings, coping ability, or number of drug-abstinent days. In a larger study reported by McDonell et al in 2013, outpatients with SMI receiving CM for stimulant drug abstinence, participants randomized to the CM condition were 2.4 times more likely than controls to submit a stimulant-negative urine sample during treatment. ${ }^{52}$ Reductions were also found in alcohol use, injecting drugs, and cigarette smoking. These findings revealed lower levels of psychiatric symptoms, and participants were five times less likely to experience psychiatric hospitalization..$^{52,56}$ Furthermore, participants who submitted a stimulant-positive sample before randomization attained briefer abstinence during CM than participants whose prerandomization samples were negative. ${ }^{57}$

Research investigating $\mathrm{CM}$ for alcohol use has been limited, in part due to methodological limitations related to alcohol breath tests being capable of assessing only very recent use (up to 12 hours). ${ }^{58,59}$ For example, one team investigated the impact of $\mathrm{CM}$ on treatment attendance and alcohol use in 20 patients, ${ }^{60}$ and no effect of CM on alcohol use was observed (ie, no breath tests were positive for alcohol use throughout the 5-month study period, despite frequent clinical reports of alcohol use). Recently however, urinary ethyl glucuronide ( $\mathrm{uEtG}$; biochemical measure of alcohol use) has been used as the basis for a CM intervention for alcohol abstinence among 79 adults with SMI. With a period of detection of up to 5 days, EtG is an ideal biomarker for a $\mathrm{CM}$ intervention focused on initiating abstinence in 
conjunction with standard intensive outpatient addiction treatment where individuals attend treatment multiple times a week. ${ }^{61,62}$ This study found that participants randomized to the CM condition were 3.1 times more likely to submit uEtG-negative samples across a 12 -week treatment period. ${ }^{6}$ More specifically, a recent secondary-data analysis assessed the interaction of type of SMI diagnosis and pretreatment drinking severity among adults randomized to a CM condition. ${ }^{63}$ Findings revealed that among heavy drinkers randomized to the $\mathrm{CM}$ condition, individuals diagnosed with major depression were more likely than individuals diagnosed with bipolar disorder or schizophrenia to submit uEtG-positive samples during treatment.

Lastly, and in line with some of the observations among patients with co-occurring addictions or MI, there is another line of developing inquiry focused on examining the "offtarget" effects of CM on co-occurring addiction behavior in an effort to leverage such observed crossover effects. In published examples of this effect, CM exhibited an apparent off-target effect on smoking among smokers who were undergoing methamphetamine-use-disorder treatment ${ }^{64}$ and a population of smokers who were also patients with SMI undergoing treatment for psychostimulant use $\mathrm{e}^{56}$ and alcohol-use disorder. ${ }^{6}$ It has also been demonstrated that $\mathrm{CM}$ indirectly reinforces treatment attendance when attendance is mandatory in order to provide the required urine sample. ${ }^{65}$ While these off-target effects are modest and likely insufficient to be considered adequate treatment options on their own, these preliminary findings offer promising pathways for additional development. We discuss this further in our conclusions at the end of this review.

\section{$\mathrm{CM}$ in diverse communities}

$\mathrm{CM}$ is effective among a diverse range of socioeconomic groups, racial and ethnic populations that include AfricanAmerican adults, and low- and middle-income countries. ${ }^{66,67}$ Indeed, there are some existing adaptations that are ongoing and worthy of note in an effort to demonstrate how CM can be easily tailored and personalized for a variety of different communities. Overall, SUD-treatment researchers have struggled to design efficacious treatment options in several diverse communities.

American Indian (AI)/Alaska Native (AN) adults have some of the highest alcohol-abstinence rates compared to the general US population. ${ }^{68,69}$ However, many AI/AN communities continue to suffer from alcohol-related health inequities. In the largest clinical trial for alcohol-use disorders among $\mathrm{AI} / \mathrm{AN}$ adults, three tribal communities partnered with university researchers to adapt and implement $\mathrm{CM}$ for alcohol-use disorders. As described by McDonell et al, ${ }^{7}$ using components of community-based participatory research and community engagement, $400 \mathrm{AI} / \mathrm{AN}$ adults will be randomized in the ongoing trial.

In another CM example, African-American adults are three times more likely to use drugs and alcohol relative to whites. ${ }^{70-72}$ African-American adults show significantly less improvement during treatment and are less likely to adhere to treatment compared to whites. These findings are not likely to be due to genetic variation, but possibly to a lack of critical preliminary work designed to address important treatment components unique to African-American communities (eg, health-behavior, cultural, and environmental factors). ${ }^{7-76}$ To our knowledge, only one study has examined the efficacy of CM for cocaine abstinence among a predominantly Hispanic $(\mathrm{n}=79)$ and African-American $(\mathrm{n}=76)$ population (whites, $\mathrm{n}=36$ ). ${ }^{66}$ Although $\mathrm{CM}$ increased abstinence among African-Americans, Hispanics, and whites compared to those in the control condition, these racial and ethnic minorities still reported a shorter duration of cocaine abstinence than whites (mean 4.1 days vs mean 5.5 days).

There has been limited research focused on determining if CM interventions are differentially effective for racial, ethnic, and other groups for whom CM could benefit from adaptation (eg, patients with co-occurring SMI, rurally dwelling patients, and patients with co-occurring SUDs) to maximize its effectiveness in treating SUDs. More preliminary work is needed to improve the acceptability and efficacy for populations with unique barriers and needs. New research is emerging, but additional research is needed to examine the efficacy and necessary adaptation of $\mathrm{CM}$ among several populations.

\section{Leveraging CM with experimental technologies}

\section{Technologies to monitor health outcomes}

In spite of its effectiveness, one barrier to be overcome for CM has been the common necessity of participants to attend visits for biochemical monitoring of recent substance use and delivery of immediate behavioral consequences (ie, obtain reinforcers). In many applications of $\mathrm{CM}$, staff must be on hand to meet participants frequently, which can be timeintensive and costly, and participants must travel to the site to supply specimens, which can be difficult in rural areas and for participants who do not have access to transport. However, mobile phones are increasingly becoming a part of everyday life, ${ }^{77}$ paving the way for new technologies to bridge this gap and allowing for progressively easier remote 
monitoring and incentive delivery through the Internet. While most technology-based CM is in the feasibility stage, significant progress has been made in remote monitoring of participants, intervention delivery, and incentive delivery through a variety of technologies.

In 2013, a randomized study assessed the feasibility and efficacy of a technology-based CM intervention to reinforce alcohol abstinence. ${ }^{78}$ This study included 30 frequently drinking adults that were given a mobile phone and portable breathalyzer and trained on how to video-record themselves giving their breath samples. Participants were randomized to either a control group that received moderate compensation for submitting timely breath samples regardless of the result or a treatment group that received the same compensation as the control group, but in addition also received CM with escalating vouchers for timely alcohol-negative breath samples. Study staff texted participants daily reminders when their breath samples were due. They found medium-large effect sizes in which CM was associated with increased alcohol abstinence, alcohol-abstinence duration, and decreases in self-reported days of drinking and drinking-problem severity during the intervention. ${ }^{78}$

Another example is a recently published smokingcessation trial that compared the efficacy of an Internet-based $\mathrm{CM}$ intervention to an Internet-based monitoring and goalsetting control intervention that did not include CM. The $\mathrm{CM}$ intervention delivered through the Internet improved short-term smoking-abstinence rates compared with the control condition. Distribution of funds happened nearly instantly after submission of negative carbon monoxide (CO; biochemical measure of recent smoking) samples. ${ }^{79}$ Another Internet-based "video-observed CO submission" program was developed specifically for Appalachian adolescents, who tend to have smoking rates that are significantly higher than the national average (ie, another population in need of adapted CM interventions). In this trial, 62 participants were asked to submit three daily video recordings showing them submitting their breath samples through a manual $\mathrm{CO}$ breathalyzer. For those in the CM condition, provision of a negative sample would earn participants electronic vouchers that could be redeemed for prizes, while those randomized to the control condition received incentives only for submitting video recordings. Although this study was carried out remotely, it still required study staff to review the video for accuracy before reinforcement was delivered. ${ }^{80}$

Another recent example of CM-related experimental technology was a computer-assisted behavioral therapy that incorporated CM for cannabis-use disorder. This trial compared motivational enhancement therapy (MET) to a combination of MET therapy, CBT, and CM that was delivered either by a therapist or by a computer. MET-CBT-CM was superior to MET alone and was just as efficacious in abstinence rates and reduction in days of use over time when delivered by computer as it was when delivered by a therapist. ${ }^{81}$ In addition, the computer-based intervention cost an average of $\$ 130$ per participant, which was significantly less than the cost of administration by a therapist. Though this intervention was not delivered online, it provides support for the continued efficacy of CM with limited human contact and could potentially be delivered remotely, resulting in increased access. Moreover, per patient costs were similar to previously reported "low-cost" CM clinical trials, speaking again to the cost-effectiveness of CM.

Lastly, a systematic review examining 39 CM-based remote-monitoring studies (18 targeting substance use, ten targeting medication adherence or home monitoring, and eleven targeting diet, exercise, or weight loss) reported that $71 \%$ of the reviewed studies resulted in significant and substantial treatment effects. These results support the benefits of remote, technology-based CM interventions for SUDs and other health behavior. ${ }^{82}$ In fact, the US Food and Drug Administration has cleared a mobile CM app for substance abuse (Pear Therapeutics Reset). ${ }^{83}$ Others are currently in development, some of which are through National Institute of Health Small Business Innovation Research and Small Business Technology Transfer programs.

In addition to experimental software technologies, there are also emerging hardware technologies that could help leverage the strengths of CM. For example, BACtrack is a battery-operated breath-alcohol analyzer that can be connected to participants' mobile phones via Bluetooth (KHN Solutions, San Francisco, CA, USA) ${ }^{84}$ This technology has not been used in conjunction with $\mathrm{CM}$ yet, but could be a valuable tool that would allow alcohol use to be monitored in much the same way as the portable $\mathrm{CO}$ analyzer utilized in the aforementioned studies. Another hardware tool for remotely monitoring alcohol use is transdermal alcohol monitoring, which removes the need for a staff member or clinician to collect a patient's samples, as the SCRAM (secure continuous remote alcohol monitoring) bracelet continuously monitors the participant's alcohol levels through an ankle monitor. ${ }^{85,86}$ This technology has been used in conjunction with $\mathrm{CM}$, but in the most recent investigations where $\mathrm{CM}$ was used to reinforce abstinence or treatment attendance in the two randomized groups, there were no differences in the primary outcomes of alcohol abstinence or attendance 
between the two groups. ${ }^{86}$ However, there have been promising data recently published about the feasibility and utility of transdermal monitoring of alcohol use..$^{78,86}$

\section{Technologies for attendance and medication adherence}

There are also emerging technologies designed to monitor medication adherence remotely, including biosensors and pill-bottle electronic monitors, ${ }^{87,88}$ another area where CM has been effectively applied in the treatment of SUDs. ${ }^{82}$ These make for encouraging developments, because treatment attendance and medication adherence are major barriers to the delivery of efficacious treatments across therapeutic areas. ${ }^{89}$ For example, a recent study assessed the feasibility of a remote medication-adherence-monitoring system with $\mathrm{CM}$ to target antidiabetic medication adherence in three adults with type 2 diabetes. Adherence to medication was recorded remotely in real time using the Wisepill, ${ }^{88}$ a portable electronically monitored pill dispenser. Monetary incentives were dependent on evidence of timely, daily medication adherence. Results indicated that adherence increased for all participants. ${ }^{79} \mathrm{CM}$ has also shown promise in improving medication adherence in HIV-positive methadone patients. ${ }^{90}$ This trial randomized participants to a comparison group (biweekly medication-adherence coaching sessions) or a voucher group (medication-adherence coaching coupled with $\mathrm{CM}$ ). The $\mathrm{CM}$ voucher group had significantly higher medication adherence compared to the comparison group. ${ }^{90}$

A 2012 systematic review of research on incentive-based interventions targeting medication adherence concluded that although CM shows promise in this field, it had been understudied. ${ }^{91}$ While a comparison among studies showed that CM interventions increased medication adherence on average by $20 \%$, effect sizes varied greatly, which may be the result of $\mathrm{CM}$ being applied nonuniformly. ${ }^{91}$ In addition, adherence to medications tended to diminish significantly after cessation of CM interventions.$^{91}$ Importantly, this evidence is not dissimilar from a variety of efficacious pharmacotherapies: they work well when being used, but the effect wears off quickly when not taken. Long-term behavior change with CM and several promising SUD therapies is an area that remains understudied.

\section{Optimizing CM for personalized interventions}

Alternative versions or optimizations of CM have been used to adequately address population-specific or tailored interventions for individuals that may need different rates, magnitudes, or schedules of reinforcement to improve
SUD-treatment outcomes significantly. For example, initial studies of CM in smokers who used cocaine demonstrated that abstinence from cigarettes or cocaine, respectively, can be better achieved by increasing the magnitude of reinforcement (ie, high-magnitude CM) or by reinforcing progressively closer estimates of abstinence (ie, shaping CM) in comparison to requiring $100 \%$ abstinence only. ${ }^{26-32,68-70}$ Some studies have utilized these methods of CM in an effort to provide varying doses of reinforcement for uniquely difficult addictions, or for individuals who have uniquely low levels of naturally occurring reinforcement and need a greater level of reinforcement to offset the highly reinforcing effects of substance use. Studies with methamphetamine-use disorder patients have also investigated whether or not altering the duration of $\mathrm{CM}$ (eg, CM for 2 months versus 4 months) or the schedule (eg, continuous schedule of reinforcement versus predictable intermittent) of CM can significantly improve long-term abstinence rates. ${ }^{13,37}$ While there is evidence that altering the rate, magnitude, and schedule can be beneficial, not all evidence points to such modifications as being different from or more beneficial than one another. We now review these optimization strategies.

Several studies have investigated the efficacy of highmagnitude $\mathrm{CM}$ in people with severe addictions. In one, nonresponders to a $\mathrm{CM}$ intervention for cocaine were exposed to high-magnitude CM (up to $\$ 3,480$ ) and usual CM (up to \$382). During high-magnitude CM, $45 \%$ attained $\geq 4$ weeks of abstinence, while only $5 \%$ achieved this goal during standard-magnitude $\mathrm{CM} .{ }^{32}$ In another study, high-magnitude $\mathrm{CM}$ increased drug abstinence in eleven treatment-resistant cocaine and opioid users. ${ }^{31}$ In both studies, participants also submitted more opiate- and benzodiazepine-negative urine samples during high-magnitude CM relative to usual-CM or usual-care conditions. In a third study, participants who submitted a pretreatment cocaine-positive urine samples (ie, a proxy measure indicating greater severity of use disorder) were randomized to usual CM (reinforcer value \$240), or high-magnitude CM (reinforcer value \$560). For those assigned to high-magnitude $\mathrm{CM}$, the duration of abstinence was more than twice as long than for those in usual care and about a week and a half longer than for those in standard CM. Lastly, a study conducted by Packer et al found that among 103 cigarette smokers, high-magnitude CM and lower preintervention smoking severity (ie, measured via cotinine, a biochemical measure of smoking severity) were both correlated with higher rates of smoking abstinence during CM. ${ }^{12,92}$

Shaping CM is an optimization strategy that reinforces reductions in use in a stepwise fashion (eg, 25\% reduction 
in use during week $1,50 \%$ reduction in use during week 2) toward eventually requiring $100 \%$ abstinence. It has been associated with better treatment outcomes in people who do not respond to $\mathrm{CM}$ interventions that required 100\% abstinence for the entire treatment period. ${ }^{26-28}$ One study randomized 95 adults to receive either 8 weeks of $\mathrm{CM}$ or 3 weeks of a shaping CM for cocaine use, in which participants were initially required to reduce cocaine metabolite levels by $25 \%$ to receive reinforcers, and then received 5 weeks of CM for $100 \%$ abstinence. ${ }^{27}$ Participants in the shaping condition had significantly higher rates of abstinence compared to the $100 \%$-abstinence group. In a series of studies conducted by Lamb et al, ${ }^{93-95}$ they reported consistent, statistically significant support for shaping CM among treatment-resistant smokers. Lamb et al used preintervention $\mathrm{CO}$ levels to personalize targets for subsequent shaping-CM schedules. In one of these trials, patients who received shaping CM submitted six times as many smoking-negative samples compared to those in the $100 \%$-abstinence CM group. ${ }^{95}$

Finally, there have been two recent investigations into the duration of CM to compare whether 1, 2, or 4 months of CM produced higher levels of methamphetamine abstinence among methamphetamine-use-disorder patients who were attending psychosocial treatment. As expected, in a stepwise fashion, longer duration of CM consistently produced proportionally better treatment outcomes not only in methamphetamine-negative urine-sample submission but also in treatment attendance. ${ }^{13}$ In a similarly designed trial, the schedule of reinforcement was manipulated to be continuous, predictable intermittent, unpredictable intermittent, or the standard CM condition. In this study, over 100 methamphetamine-use-disorder patients who were receiving psychosocial treatment found that the different schedules essentially did not impact treatment outcomes (eg, abstinence rates, attendance rates). ${ }^{37}$ This is important to consider when modifying and personalizing future interventions and further illustrates the flexibility of CM in treating SUDs. Many of these optimization strategies have not been examined in depth through additional Phase II or Phase III clinical trials across substances or different populations; however, such studies could help enormously to personalize treatment for SUDs better.

\section{Discussion}

We have reviewed in depth three core themes across the use of CM for multiple SUDs: adapting CM for underserved populations, CM with experimental technologies, and optimizing $\mathrm{CM}$ for personalized interventions. It is our hope that this will help inform future iterations of CM being utilized in multiple settings. For example, while some of the early work on magnitude, delay, and shaping produced promising results, we still do not know for whom these schedules work best or for which SUDs it may or may not work best. Additionally, there has not been enough work done on mobile-based CM systems to provide a systematic review of those studies, but this is emerging quickly, which will hopefully act as an accelerant to new and promising CM adaptations when combined with the aforementioned optimization strategies that need additional research.

Similar to all reviews, this review has its limitations, with two notable weaknesses. First, this review did not focus on much of the promising work on combining CM with various psychotherapies and medications. This is an important emerging area that will likely leverage further some of the developments discussed herein, as it adds a layer of optimization potential for different patient populations (eg, those with more than one addiction). Another possible limitation of this review is that we chose not to conduct a quantitative meta-analysis. Such reviews can be instrumental when wanting to quantify the effect of a treatment across settings, samples, and other factors. In this review, we deliberately chose to focus our review on three a priori-selected themes in an effort to build on the excellent work already published on the consistent, strong effects of $\mathrm{CM}$ across various factors. Our objective with this review was to build on that work and expose readers to novel possibilities in the application of CM across SUDs.

One of the biggest barriers to utilizing $\mathrm{CM}$ in real-world treatment situations effectively is not a scientific one, but a political one. Convincing policy makers of why this should be more broadly integrated into drug- and alcohol-use-disorder treatment has proven difficult. However, CM interventions are being applied in clinical practices throughout the US and UK. For example, CM is being increasingly used as the SUD treatment of choice within the US Veterans Administration system. ${ }^{96}$ Since 2011, the Veterans Administration has successfully integrated CM into 70 of its intensive outpatient substance-abuse-treatment clinics for veterans. ${ }^{96}$ At the same time, the National Health Service in the UK has also implemented CM into its SUD-treatment guidelines. ${ }^{97}$ Investigations of CM dissemination are under way, including studies designed to understand systemic and clinician variables that impede or facilitate CM implementation better. ${ }^{98-104}$ One of the most important pieces of evidence that has emerged in the CM literature, especially in light of the political challenges, is that it is a cost-effective treatment option..$^{23-26,28}$ In theory, 
this should lead to greater adoption across the US health care system, in desperate search of economically viable alternatives in the face of scarce and diminishing resources. More economic work on $\mathrm{CM}$ is under way that should contribute to this discussion.

Finally, one last important aspect of CM that makes it amenable to several different adaptations and optimizations using the aforementioned emerging utilities is that CM produces virtually no adverse events. In fact, Petry et al ${ }^{96}$ examined 260 serious adverse events across two large ${ }^{105}$ national multisite CM trials (along with two other psychosocial intervention investigations) and found that none was judged by the Data Safety and Monitoring Board to be related to the CM intervention. This makes CM both effective and amenable to ongoing experimentation and optimization efforts across a diverse array of settings and populations that will only be leveraged further by ongoing technological developments.

\section{Acknowledgments}

SMM and JMR have received research funding from the Bristol-Myers Squibb Foundation. SMM has also received research funding from the Orthopedic Specialty Institute and consulted for Consistent Care. This funding is in no way related to the investigation reported here. This project was supported by grants N44 DA171210 and N44 DA162246 (SMM), P20 MD006871 (SMM), R01 AA020248 (MGM), R01 AA022070 (MGM), and R01 DA170884, R01 DA 017407, and R01 017084 (JMR). These funding sources had no role other than financial support.

\section{Disclosure}

The authors report no conflicts of interest in this work.

\section{References}

1. Bigelow GE, Silverman K. Theoretical and empirical foundations of contingency management treatments for drug abuse. In: Higgins ST, Silverman K, editors. Motivating Behavior Change among IllicitDrug Abusers: Research on Contingency Management Interventions. Washington: American Psychological Association; 1999:15-31.

2. Bigelow G, Liebson I. Behavioral contingencies controlling alcoholics' drinking. Alcoholism. 1973;9:24-28.

3. Bigelow GE, Liebson I. Cost factors controlling alcoholic drinking. Psychol Rec. 1972;22(3):305-314.

4. Cohen M, Liebson IA, Faillace LA, Allen RP. Moderate drinking by chronic alcoholics: a schedule-dependent phenomenon. J Nerv Ment Dis. 1971;153(6):434-444.

5. Cohen M, Liebson IA, Faillace LA, Speers W. Alcoholism: controlled drinking and incentives for abstinence. Psychol Rep. 1971;28(2):575-580.

6. McDonell M, Leickly E, McPherson S, et al. A randomized controlled trial of ethyl glucuronide-based contingency management for outpatients with co-occurring alcohol use disorders and serious mental illness. Am J Psychiatry. 2017;174(4):370-377.
7. McDonell MG, Nepom JR, Leickly E, et al. A culturally-tailored behavioral intervention trial for alcohol use disorders in three American Indian communities: rationale, design, and methods. Contemp Clin Trials. 2016;47:93-100.

8. Birnbrauer JS, Wolf MM, Kidder J, Tague CE. Classroom behavior of retarded pupils with token reinforcement. J Exp Child Psychol. 1965;2(2):219-235.

9. Elliott R, Tighe T. Breaking the cigarette habit: effects of a technique involving threatened loss of money. Psychol Rec. 1968;18(4):503-513.

10. Stitzer M, Bigelow G. Contingency management in a methadone maintenance program: availability of reinforcers. Int $J$ Addict. 1978;13(5):737-746.

11. Dutra L, Stathopoulou G, Basden SL, Leyro TM, Powers MB, Otto MW. A meta-analytic review of psychosocial interventions for substance use disorders. Am J Psychiatry. 2008;165(2):179-187.

12. Packer RR, Howell DN, McPherson S, Roll JM. Investigating reinforcer magnitude and reinforcer delay: a contingency management analog study. Exp Clin Psychopharmacol. 2012;20(4):287-292.

13. Roll JM, Chudzynski J, Cameron JM, Howell DN, McPherson S. Duration effects in contingency management treatment of methamphetamine disorders. Addict Behav. 2013;38(9):2455-2462.

14. Winhusen TM, Brigham GS, Kropp F, et al. A randomized trial of concurrent smoking-cessation and substance use disorder treatment in stimulant-dependent smokers. J Clin Psychiatry. 2014;75(4):336-343.

15. Higgins ST, Petry NM. Contingency management: incentives for sobriety. Alcohol Res Health. 1999;23(2):122-127.

16. Higgins ST, Heil SH, Lussier JP. Clinical implications of reinforcement as a determinant of substance use disorders. Annu Rev Psychol. 2004;55:431-461.

17. Petry NM, Peirce JM, Stitzer ML, et al. Effect of prize-based incentives on outcomes in stimulant abusers in outpatient psychosocial treatment programs: a National Drug Abuse Treatment Clinical Trials Network study. Arch Gen Psychiatry. 2005;62(10):1148-1156.

18. Peirce JM, Petry NM, Stitzer ML, et al. Effects of lower-cost incentives on stimulant abstinence in methadone maintenance treatment: a National Drug Abuse Treatment Clinical Trials Network study. Arch Gen Psychiatry. 2006;63(2):201-208.

19. Businelle MS, McVay MA, Kendzor D, Copeland A. A comparison of delay discounting among smokers, substance abusers, and nondependent controls. Drug Alcohol Depend. 2010;112(3):247-250.

20. McClure SM, Laibson DI, Loewenstein G, Cohen JD. Separate neural systems value immediate and delayed monetary rewards. Science. 2004;306(5695):503-507.

21. Bechara A. Decision making, impulse control and loss of willpower to resist drugs: a neurocognitive perspective. Nat Neurosci. 2005;8(11):1458-1463.

22. Stevens L, Verdejo-García A, Roeyers H, Goudriaan AE, Vanderplasschen W. Delay discounting, treatment motivation and treatment retention among substance-dependent individuals attending an in inpatient detoxification program. $J$ Subst Abuse Treat. 2015;49:58-64.

23. Murphy SM, McDonell MG, McPherson S, et al. An economic evaluation of a contingency-management intervention for stimulant use among community mental health patients with serious mental illness. Drug Alcohol Depend. 2015;153:293-299.

24. Olmstead TA, Petry NM. The cost-effectiveness of prize-based and voucher-based contingency management in a population of cocaine- or opioid-dependent outpatients. Drug Alcohol Depend. 2009;102(1-3): 108-115.

25. Olmstead TA, Sindelar JL, Petry NM. Clinic variation in the costeffectiveness of contingency management. Am J Addict. 2007;16(6): 457-460.

26. Olmstead TA, Sindelar JL, Easton CJ, Carroll KM. The costeffectiveness of four treatments for marijuana dependence. Addiction. 2007;102(9):1443-1453.

27. Olmstead TA, Johnson JA, Roman PM, Sindelar JL. Why are recovering substance abuse counselors paid less? Subst Abus. 2007;28(1):31-44. 
28. Olmstead TA, Sindelar JL, Petry NM. Cost-effectiveness of prize-based incentives for stimulant abusers in outpatient psychosocial treatment programs. Drug Alcohol Depend. 2007;87(2-3):175-182.

29. Stitzer ML, Bigelow GE, Liebson I. Reinforcement of drug abstinence: a behavioral approach to drug abuse treatment. NIDA Res Monogr. 1979;(25):68-90.

30. Higgins ST, Budney AJ, Bickel WK, Foerg FE, Donham R, Badger GJ. Incentives improve outcome in outpatient behavioral treatment of cocaine dependence. Arch Gen Psychiatry. 1994;51(7):568-576.

31. Stitzer ML, Rand CS, Bigelow GE, Mead AM. Contingent payment procedures for smoking reduction and cessation. J Appl Behav Anal. 1986;19(2):197-202.

32. Higgins ST, Stitzer ML, Bigelow GE, Liebson IA. Contingent methadone delivery: effects on illicit-opiate use. Drug Alcohol Depend. 1986;17(4):311-322.

33. Robles E, Stitzer ML, Strain EC, Bigelow GE, Silverman K. Voucherbased reinforcement of opiate abstinence during methadone detoxification. Drug Alcohol Depend. 2002;65(2):179-189.

34. Budney AJ, Higgins ST, Radonovich KJ, Novy PL. Adding voucherbased incentives to coping skills and motivational enhancement improves outcomes during treatment for marijuana dependence. J Consult Clin Psychol. 2000;68(6):1051-1061.

35. Kadden RM, Litt MD, Kabela-Cormier E, Petry NM. Abstinence rates following behavioral treatments for marijuana dependence. Addict Behav. 2007;32(6):1220-1236.

36. Roll JM. Contingency management: an evidence-based component of methamphetamine use disorder treatments. Addiction. 2007;102 Suppl 1:114-120.

37. Chudzynski J, Roll JM, McPherson S, Cameron JM, Howell DN. Reinforcement schedule effects on long-term behavior change. Psychol Rec. 2015;65(2):347-353.

38. Prendergast M, Podus D, Finney J, Greenwell L, Roll J. Contingency management for treatment of substance use disorders: a meta-analysis. Addiction. 2006;101(11):1546-1560.

39. Dutra L, Stathopoulou G, Basden SL, et al. A meta-analytic review of psychosocial interventions for substance use disorders. Am J Psychiatry. 2008;165(2):179-187.

40. Lussier JP, Heil SH, Mongeon JA, Badger GJ, Higgins ST. A metaanalysis of voucher-based reinforcement therapy for substance use disorders. Addiction. 2006;101(2):192-203.

41. Rawson RA, McCann MJ, Flammino F, et al. A comparison of contingency management and cognitive-behavioral approaches for stimulant-dependent individuals. Addiction. 2006;101(2):267-274.

42. Higgins ST, Wong CJ, Badger GJ, Ogden DE, Dantona RL. Contingent reinforcement increases cocaine abstinence during outpatient treatment and 1 year of follow-up. J Consult Clin Psychol. 2000;68(1):64-72.

43. Preston KL, Umbricht A, Epstein DH. Abstinence reinforcement maintenance contingency and one-year follow-up. Drug Alcohol Depend. 2002;67(2):125-137.

44. Reback CJ, Peck JA, Dierst-Davies R, Nuno M, Kamien JB, Amass L. Contingency management among homeless, out-of-treatment men who have sex with men. J Subst Abuse Treat. 2010;39(3): 255-263.

45. Kalman D, Kim S, DiGirolamo G, Smelson D, Ziedonis D. Addressing tobacco use disorder in smokers in early remission from alcohol dependence: the case for integrating smoking cessation services in substance use disorder treatment programs. Clin Psychol Rev. 2010;30(1):12-24.

46. Saxon A, McCarty D. Challenges in the adoption of new pharmacotherapeutics for addiction to alcohol and other drugs. Pharmacol Ther. 2005;108(1):119-128.

47. Saxon AJ, Ling W, Hillhouse M, et al. Buprenorphine/naloxone and methadone effects on laboratory indices of liver health: a randomized trial. Drug Alcohol Depend. 2013;128(1-2):71-76.

48. Saxon AJ, McGuffin R, Walker RD. An open trial of transdermal nicotine replacement therapy for smoking cessation among alcohol- and drug-dependent inpatients. J Subst Abuse Treat. 1997;14(4):333-337.
49. Weisner C, Ray GT, Mertens JR, Satre DD, Moore C. Short-term alcohol and drug treatment outcomes predict long-term outcome. Drug Alcohol Depend. 2003;71(3):281-294.

50. Higgins ST, Badger GJ, Budney AJ. Initial abstinence and success in achieving longer term cocaine abstinence. Exp Clin Psychopharmacol. 2000;8(3):377-386.

51. Carroll KM, Nich C, Ball SA, McCance E, Frankforter TL, Rounsaville BJ. One-year follow-up of disulfiram and psychotherapy for cocaine-alcohol users: sustained effects of treatment. Addiction. 2000;95(9):1335-1349.

52. McDonell MG, Srebnik D, Angelo F, et al. Randomized controlled trial of contingency management for stimulant use in community mental health patients with serious mental illness. Am J Psychiatry. 2013;170(1):94-101

53. Bellack AS, Bennett ME, Gearon JS, Brown CH, Yang Y. A randomized clinical trial of a new behavioral treatment for drug abuse in people with severe and persistent mental illness. Arch Gen Psychiatry. 2006;63(4):426-432.

54. Ries RK, Dyck DG, Short R, Srebnik D, Fisher A, Comtois KA. Outcomes of managing disability benefits among patients with substance dependence and severe mental illness. Psychiatr Serv. 2004;55(4):445-447.

55. Kelly TM, Daley DC, Douaihy AB. Contingency management for patients with dual disorders in intensive outpatient treatment for addiction. J Dual Diagn. 2014;10(3):108-117.

56. McDonell M, McPherson S, Vilardaga R, et al. Preliminary findings: contingency management targeting psycho-stimulant use results in secondary decreases in smoking for severely mentally ill adults. $\mathrm{Am}$ $J$ Addict. 2014;23(4):407-410.

57. Angelo FN, McDonell MG, Lewin MR, et al. Predictors of stimulant abuse treatment outcomes in severely mentally ill outpatients. Drug Alcohol Depend. 2013;131(1):162-165.

58. Higgins ST, Petry NM. Contingency management. Incentives for sobriety. Alcohol Res Health. 1999;23(2):122-127.

59. Warner EA, Sharma N. Laboratory diagnosis. In: Ries RK, Fiellin DA, Miller SC, Saitz R, editors. Principles of Addiction Medicine. 4th ed. Philadelphia: Lippincott Williams \& Wilkins; 2009:295-304.

60. Helmus TC, Saules KK, Schoener EP, Roll JM. Reinforcement of counseling attendance and alcohol abstinence in a community-based dual-diagnosis treatment program: a feasibility study. Psychol Addict Behav. 2003;17(3):249-251.

61. Lowe JM, McDonell MG, Leickly E, et al. Determining ethyl glucuronide cutoffs when detecting self-reported alcohol use in addiction treatment patients. Alcohol Clin Exp Res. 2015;39(5):905-910.

62. McDonell MG, Skalisky J, Leickly E, et al. Using ethyl glucuronide in urine to detect light and heavy drinking in alcohol dependent outpatients. Drug Alcohol Depend. 2015;157:184-187.

63. Oluwoye O, Leickly E, Skalisky J, et al. Serious mental illness in heavy drinkers is associated with poor treatment outcomes in outpatients with co-occurring disorders. Int J Ment Health Addict. Epub 2017 Oct 31 .

64. McPherson S, Orr M, Lederhos C, et al. Decreases in smoking during treatment for methamphetamine-use disorders: preliminary evidence. Behav Pharmacol. Epub 2017 Oct 13.

65. McPherson S, Brooks O, Barbosa-Leiker C, et al. Examining longitudinal stimulant use and treatment attendance as parallel outcomes in two contingency management randomized clinical trials. J Subst Abuse Treat. 2016;61:18-25.

66. Barry D, Sullivan B, Petry NM. Comparable efficacy of contingency management for cocaine dependence among African American, Hispanic, and white methadone maintenance clients. Psychol Addict Behav. 2009;23(1):168-174.

67. Miguel AQ, Madruga CS, Cogo-Moreira H, et al. Contingency management is effective in promoting abstinence and retention in treatment among crack cocaine users in Brazil: a randomized controlled trial Psychol Addict Behav. 2016;30(5):536-543. 
68. Spicer P, Beals J, Croy CD, et al. The prevalence of DSM-III-R alcohol dependence in two American Indian populations. Alcohol Clin Exp Res. 2003;27(11):1785-1797.

69. Cunningham JK, Solomon TA, Muramoto ML. Alcohol use among Native Americans compared to whites: examining the veracity of the 'Native American elevated alcohol consumption' belief. Drug Alcohol Depend. 2016;160:65-75.

70. Padgett DK, Stanhope V, Henwood BF, Stefancic A. Substance use outcomes among homeless clients with serious mental illness: comparing housing first with treatment first programs. Community Men Health J. 2011;47(2):227-232.

71. Castro FG, Proescholdbell RJ, Abeita L, Rodriguez D. Ethnic and cultural minority groups. In: McCrady BS, Epstein EE, editors. Addictions: A Comprehensive Guidebook. New York: Oxford University Press; 1999:499-526.

72. Compton WM, Cottler LB, Abdallah A, Phelps DL, Spitznagel EL, Horton JC. Substance dependence and other psychiatric disorders among drug dependent subjects: race and gender correlates. $\mathrm{Am} \mathrm{J}$ Addict. 2000;9(2):113-125.

73. Aoude A, Kearney R, Brown K, Galiana H, Robles-Rubio C. Automated off-line respiratory event detection for the study of postoperative apnea in infants. IEEE Trans Biomed Eng. 2011;58(6):1724-1733.

74. Williams DR, Earl TR. Commentary: race and mental health - more questions than answers. Int J Epidemiol. 2007;36(4):758-760.

75. Gary FA. Stigma: barrier to mental health care among ethnic minorities. Issues Ment Health Nurs. 2005;26(10):979-999.

76. Opolka JL, Rascati KL, Brown CM, Gibson PJ. Role of ethnicity in predicting antipsychotic medication adherence. Ann Pharmacother. 2003;37(5):625-630.

77. Smith-Jackson T, Nussbaum M, Mooney A. Accessible cell phone design: development and application of a needs analysis framework. Disabil Rehabil. 2003;25(10):549-560.

78. Alessi SM, Petry NM. A randomized study of cellphone technology to reinforce alcohol abstinence in the natural environment. Addiction. 2013;108(5):900-909.

79. Dallery J, Raiff BR, Kim SJ, Marsch LA, Stitzer M, Grabinski MJ. Nationwide access to an internet-based contingency management intervention to promote smoking cessation: a randomized controlled trial. Addiction. 2017;112(5):875-883.

80. Reynolds B, Harris M, Slone SA, et al. A feasibility study of homebased contingency management with adolescent smokers of rural Appalachia. Exp Clin Psychopharmacolacol. 2015;23(6):486-493.

81. Budney AJ, Stanger C, Tilford JM, et al. Computer-assisted behavioral therapy and contingency management for cannabis use disorder. Psychol Addict Behav. 2015;29(3):501-511.

82. Kurti AN, Davis D, Redner R, et al. A review of the literature on remote monitoring technology in incentive-based interventions for healthrelated behavior change. Transl Issues Psychol Sci. 2016;2(2):128-152.

83. US Food and Drug Administration [webpage on the Internet]. FDA permits marketing of mobile medical application for substance use disorder. 2017. Available from: https://www.fda.gov/NewsEvents/Newsroom/ PressAnnouncements/ucm576087.htm. Accessed November 3, 2017.

84. Ran R, Mullins ME. Can handling E85 motor fuel cause positive breath alcohol test results? J Anal Toxicol. 2013;37(7):430-432.

85. Barnett NP, Tidey J, Murphy JG, Swift R, Colby SM. Contingency management for alcohol use reduction: a pilot study using a transdermal alcohol sensor. Drug Alcohol Depend. 2011;118(2):391-399.

86. Alessi SM, Barnett NP, Petry NM. Experiences with SCRAMx alcohol monitoring technology in 100 alcohol treatment outpatients. Drug Alcohol Depend. 2017;178:417-424.
87. Flores GP, Peace B, Carnes TC, et al. Performance, reliability, usability, and safety of the ID-Cap system for ingestion event monitoring in healthy volunteers: a pilot study. Innov Clin Neurosci. 2016;13(9-10):12-19.

88. Raiff BR, Jarvis BP, Dallery J. Text-message reminders plus incentives increase adherence to antidiabetic medication in adults with type 2 diabetes. J Appl Behav Anal. 2016;49(4):947-953.

89. Kimmel SE, Troxel AB. Novel incentive-based approaches to adherence. Clin Trials. 2012;9(6):689-695.

90. Sorensen JL, Haug NA, Delucchi KL, et al. Voucher reinforcement improves medication adherence in HIV-positive methadone patients: a randomized trial. Drug Alcohol Depend. 2007;88(1):54-63.

91. DeFulio A, Silverman K. The use of incentives to reinforce medication adherence. Prev Med. 2012;55 Suppl:S86-S94.

92. McPherson S, Packer RR, Cameron JM, Howell DN, Roll JM. Biochemical marker of use is a better predictor of outcomes than self-report metrics in a contingency management smoking cessation analog study. Am J Addict. 2014;23(1):15-20.

93. Lamb RJ, Morral AR, Kirby KC, Iguchi MY, Galbicka G. Shaping smoking cessation using percentile schedules. Drug Alcohol Depend. 2004;76(3):247-259.

94. Lamb RJ, Morral AR, Galbicka G, Kirby KC, Iguchi MY. Shaping reduced smoking in smokers without cessation plans. Exp Clin Psychopharmacolacol. 2005;13(2):83-92.

95. Lamb RJ, Kirby KC, Morral AR, Galbicka G, Iguchi MY. Shaping smoking cessation in hard-to-treat smokers. J Consult Clin Psychol. 2010;78(1):62-71.

96. Petry NM, DePhilippis D, Rash CJ, Drapkin M, McKay JR. Nationwide dissemination of contingency management: the Veterans Administration initiative. Am J Addict. 2014;23(3):205-210.

97. Pilling S, Strang J, Gerada C. NICE guidelines: psychosocial interventions and opioid detoxification for drug misuse: summary of NICE guidance. BMJ. 2007;335(7612):203-205.

98. Henggeler SW, Chapman JE, Rowland MD, et al. Statewide adoption and initial implementation of contingency management for substanceabusing adolescents. J Consult Clin Psychol. 2008;76(4):556-567.

99. Bride BE, Abraham AJ, Roman PM. Diffusion of contingency management and attitudes regarding its effectiveness and acceptability. Subst Abuse. 2010;31(3):127-135.

100. Bride BE, Abraham AJ, Roman PM. Organizational factors associated with the use of contingency management in publicly funded substance abuse treatment centers. $J$ Subst Abuse Treat. 2011;40(1):87-94.

101. Walker R, Rosvall T, Field CA, et al. Disseminating contingency management to increase attendance in two community substance abuse treatment centers: lessons learned. J Subst Abuse Treat. 2010;39(3):202-209.

102. Kirby KC, Benishek LA, Dugosh KL, Kerwin ME. Substance abuse treatment providers' beliefs and objections regarding contingency management: implications for dissemination. Drug Alcohol Depend. 2006;85(1):19-27.

103. Kellogg SH, Burns M, Coleman P, Stitzer M, Wale JB, Kreek MJ. Something of value: the introduction of contingency management interventions into the New York City Health and Hospital Addiction Treatment Service. J Subst Abuse Treat. 2005;28(1):57-65.

104. Ducharme LJ, Knudsen HK, Abraham AJ, Roman PM. Counselor attitudes toward the use of motivational incentives in addiction treatment. Am J Addict. 2010;19(6):496-503.

105. Petry NM, Roll JM, Rounsaville BJ, et al. Serious adverse events in randomized psychosocial treatment studies: safety or arbitrary edicts? J Consult Clin Psychol. 2008;76(6):1076-1082. 
Substance Abuse and Rehabilitation is an international, peer-reviewed, open access journal publishing original research, case reports, editorials, reviews and commentaries on all areas of addiction and substance abuse and options for treatment and rehabilitation. The manuscript management system is completely online and includes a very quick and fair peer-review system. Visit http://www.dovepress.com/testimonials.php to read real quotes from published authors.

Submit your manuscript here: https://www.dovepress.com/substance-abuse-and-rehabilitation-journal 